\title{
Privacy, Character, and Community
}

\author{
Firmin DeBrabander*
}

As a parent and teacher, I have been in a constant struggle against digital technology-before Covid, that is. In class, I was generally averse to my students using their laptops, for fear they would get distracted and surf the web; and I was adamant that their cellphones be safely stowed away, in pockets or backpacks. There is nothing more distracting in class than a phone ringing, or vibrating, or nervous students checking for updates instinctively and repeatedly.

I have waged the latter fight with my own children, too, who find any excuse to check their cellphones. They seem to love nothing more than an endless stream of nonsensical videos on Youtube or Tiktok. Cellphones are the ultimate time waster, when I want my kids to enjoy a beautiful day outside, or focus on homework, and finish at a reasonable hour.

Covid turned my universe upside down. Since the pandemic put many American schools online-higher and lower education alike-my children and I have been marooned at home, learning and teaching remotely. I have had to accept, and indeed urge that my students be on their laptops-all the time. My children, too, have been glued to their computers; and I must tolerate the constant presence of their cellphones, which they require for school notifications, and collaboration with classmates.

Six months in to the pandemic, a third of Americans work online. ${ }^{1}$ For many, it has offered a welcome respite from stressful commutes. Businesses have found a silver lining, too: if more people can work from home, this means less need for pricey office space. We will likely continue to see greater numbers of people work from home in the future.

And shop from home, too. Commercial real estate faces a potentially dim future since the pandemic forced people to rely on digital retail services, and learn new habits of shopping. Honestly, it has been rather glorious having groceries delivered right to my front door; I can get used to that kind of convenience going forward. I likely will.

In sum, the pandemic has inaugurated new habits of living, learning and work, many of which are here to stay-digital habits, to be precise. And there is another impor-

* Firmin DeBrabander is a professor of philosophy at the Maryland Institute College of Art. For Correspondence: <fdebrabander@mica.edu>

1 Radmilla Suleymanova, "As new wave of Covid-19 cases hits, remote work becomes the norm," Aljazeera.com, October 18, 2020, https://www.aljazeera.com/economy/2020/10/18/with-new-lockdowns-looming-remote-work-feels-like-forever. 
tant, if lesser noticed casualty in this grueling year: privacy. Covid has accelerated our dependence on media that, of their nature, make our personal information vulnerable.

Privacy advocates are rightly worried about this state of affairs. And this is to say nothing of the vast surveillance programs that many countries mobilized to corral the disease-surveillance that is also here to stay, and likely modeled by other nations. Thus far, privacy advocates have championed regulations - like the EU's GDPR - that give greater power to individual consumers, so they may better protect their data. This is a short-handed approach to the threat before us, however. Lone individuals are no match for the multinational companies deeply invested in spying on us, collecting and analyzing our data. The science of Big Data is arcane indeed, and far outstrips the imagination of the average consumer and citizen.

The task of defending privacy is far more expansive than advocates suggest, or perhaps accept. It may require nothing less than a profound cultural change, where we align with collective bodies - and communities - that empower us politically, and nourish us morally. When I raise the issue of privacy with my college students or teenage children, I get the same response: why should I care what spies see? My digital behavior is innocuous, my son says-how can they use it against me? Who cares if they know the toothpaste I buy, the music I listen to-the silly, harmless, and sometimes rude jokes I share with friends on social media?

The concern, of course, is that surveillance leads to manipulation; armed with intimate knowledge, my spies may then try to push my buttons. Knowing what I want, they will tempt me, seduce me. Thanks to their stealth influence, I may be none the wiser-and I will continue to believe I am making free choices in what I purchase, though my free will is slowly sapped.

This is the threat we face in liberal democracies; political philosophers, however, do not tire of warning us this could easily take a more sinister turn, and surveillance might deliver us again to those chilling regimes of the mid $20^{\text {th }}$ century-Stalinist Russia, Maoist China-where surveillance was a prime measure of coercion.

Luckily in the West, we are not there-yet. For the moment, we are plagued by private sector spies, especially retailers, who are hungry to mold our tastes and shopping habits. How shall we retain or protect free will from these vultures?

"The most important determinant" of an individual's ability to withstand digital manipulation and the persuasion of marketers, researchers have concluded, is "the ability to premeditate." ${ }^{2}$ In other words, when we reflect carefully, thoughtfully on our needs and desires - when we are fully cognizant of the choices before us, how they

2 Shoshana Zuboff, The Age of Surveillance Capitalism (New York: Public Affairs, 2019), 308. 
fit into our lives, or not-then we may better retain a degree of self-control. Said reflection, however, is an increasingly rare commodity in the digital economy, which moves at light speed. To cope, we are constantly urged to outsource premeditation, reflection, and choice.

Many rely on digital assistants, which promise to organize our obligations, and help us navigate busy personal and professional schedules. Amazon's Alexa, Apple's Siri, and Google Assistant insinuate themselves into our lives, and learn everything they can from the variety and confluence of digital services we use-our internet searches, emails, and digital calendar, also the cell phone data that reveal our movements and activity, the apps we frequent, when, how, and why. The goal is to achieve anticipatory knowledge, privacy scholar Shoshana Zuboff explains: our digital assistants will grasp what we want before we ask—even before we know we want it.

A Google executive illustrated the ambition for their digital assistant thus: "you can be in front of this structure in Chicago and ask Google 'Who designed this?' You don't need to say 'the bean' or 'the cloud gate' [a popular sculpture downtown]. We understand from your context and we answer that the designer is Anish Kapoor." ${ }^{3}$ Knowing your hobbies, interests and personal tastes-also your schedule for the rest of the day-Google Assistant may next recommend a nearby restaurant, store, movie, or play.

Some digital assistants are highly - preternaturally-interactive, which makes us more likely to divulge instinctively, impulsively, unthinkingly. In the easy, fluid exchange with Alexa, as you rush around the kitchen on a busy weekday morning, perhaps voicing angst and frustration, dreaming of a holiday, Amazon expects you will reveal all manner of sensitive information, and secret yearnings and fantasies. The fact that we can interact with digital assistants absent the eyes of our peers suggests we may be more forthcoming - and shameless. Alexa will not judge. Liberated from the mediation and interruption of flesh and blood salespersons, Amazon wagers we will be more inclined to make purchases on the spot, or on a whim. And Amazon neatly sidesteps our busy schedule, when we might allot precious time to visit the shopping mall, and deliberate over purchases that fit our budget and taste.

We are inclined, even overjoyed, to rely on Alexa and Google Assistant because life in $21^{\text {st }}$ century digital economies is so hectic. It's a relief to be spared the tedium and effort of deliberation. Workweeks in America are still growing-digital media enables us to work more efficiently, but we have not used said efficiency to lighten our schedules. Americans generally take advantage of the time saved to work more, any time of day or night, from any number of places (how often have I answered work emails from the sidelines of my son's soccer game?). Before the pandemic, we endured lengthy commutes; many will still do so, I imagine. American parents spend much time in the car after work is done, ferrying children to sports practice, music lessons, and the like. 
Digital assistants fit neatly into our tight schedules, help us juggle it all_and take on more.

It is easy to see how privacy is endangered under these circumstances. We are not disposed, inclined, or accustomed to take the time to protect our privacy, much less consider it. We are rushed about -happily taking advantages of digital conveniences to move still faster-and constantly dissuaded from relying on inner resources that would muster a defense of our sensitive personal information.

Even if we had time to reflect, and carefully assess our digital lures, we face another challenge: what the data analysts know about us, what they glean from our digital trails and habits, is nearly impossible to understand and anticipate, manage, and possibly repel. It is a tall order, expecting us to deliberate over what information to share with the behemoths who monitor us, and seemingly predict our behavior.

This is just what privacy regulations hope for, however. The GDPR, which civil libertarians across the global applaud, requires companies to provide documentation explaining what they are collecting and why, how long they will hold it, and how they will protect it. Unlike the US, where consumers must opt-out of data collection when they visit a website, the GDPR requires consumers to opt-in. In general, the regulations aim to make data collection foremost in our minds, as opposed to an afterthought we can easily ignore, as we navigate the high-speed digital universe. We are to be constantly reminded that data is collected, and we are told how it is to be used.

Except that we can never really understand the latter. The average consumer and citizen cannot be plausibly empowered to comprehend and discern the fate of our data-and how it will impact us. One retailer, for example, has determined that purchasing "felt pads to keep our furniture from scuffing the floor" is a key indicator of creditworthiness. ${ }^{4}$ Analysts conclude otherwise if we fill out loan applications in all capital letters, or include words like 'promise,' 'will pay,' or 'hospital. ${ }^{5}$ Upon reflection, these indicators make some sense: if a person is sufficiently anal retentive to protect his floors from offending furniture, then surely he will mind his bank account.

Harder to fathom, however, is how data analysts determine creditworthiness from mining our smartphone behavior. They pay attention to how often we change our phone battery, how many messages we receive, if we are solicitous of returning phone calls, and how many contacts are on our phones. What do they learn from it all? And if companies were to patiently explain the madness of their method-if they were to slowly lead me through it step by step so I could grasp their insight-how soon will their science change? How soon will they identify a new set of key indicators?

4 Gordon Hull, "Successful failure: What Foucault can teach us about privacy self-management in a world of Facebook and Big Data," Ethics and Information Technology 17/2 (2015), 90.

5 Deborah Gage, "Big Data uncovers some weird correlations," Wall Street Journal, March 23, 2014, https://www.wsj.com/articles/SB10001424052702303369904579423132072969654; Seth Stephens-Davidowitz, Everybody Lies (New York: Dey St., 2017$), 258$. 
Besides, Big Data does not need our data at all—metadata will do. Analysts believe they can learn plenty about us from the mere form of our communications and digital behavior, not the substance. For example, Zuboff tells us, an insurance company will soon determine your premium not on the basis of "what you write but how you write it. It is not what is in your sentences, but in their length and complexity, not what you list, but that you list, not the picture but the choice of filter and degree of saturation, not what you disclose but how you share or fail to..." ${ }^{6}$

In fact, you don't even need to be online. Facebook compiles shadow profiles of people whose existence is merely invoked on the social media platform. What to do? For starters, we might heed those researchers who highlight the importance of reflection. When we are accustomed to deliberating over the choices offered to us, when we weigh our options, consider how they impact us according to our needs and wants, and if they fit with a carefully thought out future, then we retain some autonomy, and a degree of self-control.

Specifically, we must develop habits of reflection, as Aristotle puts it. Virtue is rooted in character, he argues-which is, in turn, founded on habits. When they are repeatedly practiced, said habits become second nature. Thus, Aristotle would advise that we again start to practice habits of deliberation, when faced with online temptation, and surveillance. We might learn to pause, and think, and wait, before acceding to the invitations of our spies. The problem is, as described above, the digital economy is so fast that it precludes the possibility for reflection. It invites us to take advantage of its speed, and in the process, we spurn the option to pause.

Character is the solution-reflection is the right response-but again, the problem is the individual. Individuals alone are no match for the fabulously rich and powerful spies who prey on us all, and the frightening speed of the digital economy that gives no one time to breathe, think, reconsider, and evaluate.

Luckily, Aristotle reminds us, character is also the fruit of community; and that is where we must ultimately turn if we wish to resist surveillance, and its attendant perils. Individuals are not the basic unit of democracy, the American philosopher John Dewey argued-associations are. ${ }^{7}$ Associations alone can stand up to powerful agents and interests in the public and private sectors alike. Associations empower, and cultivate, impactful citizens.

Democratic citizens are principally a social product and entity, as Dewey saw it. Which is to say, they are produced through social interaction, and they exert power socially - through associations. Citizens are not magically conceived on their own, as if in a private bubble, if you will. They are not made by simply giving people space,

6 Zuboff, 275

7 John Dewey, The Public and its Problems (University Park, Pennsylvania: The Pennsylvania State University Press, 2012), 92. 
time, and peace. No, citizens are forged through interaction and communication, habits of negotiation, and the practice of struggle. This is where autonomy emerges-not in being left alone, as privacy advocates suggest. ${ }^{8}$

Dewey understood associations expansively. They may include social clubs, labor unions, political advocacy groups of many stripes and flavors, also churches, mosques and synagogues. Associations impart democratic training for their members, even when said associations are not themselves democratic through and through. Often, they are not-churches are a case in point. Nevertheless, these associations nurture democratic character. They offer members plentiful opportunities to learn how to negotiate differences, and manage sometimes delicate and strained coordination. Associations instruct how to mobilize, and in so doing, encourage and embolden individual citizens, who would be less inclined, and certainly less knowledgeable, to mobilize on their own. Associations, Dewey believed, help us define ourselves, address and compete with opponents, and challenge authority-credibly. Entrenched powers are more likely to heed, and perhaps fear, coordinated citizen action, not the demands of isolate private individuals.

Though embattled today-especially in the US - labor unions are a key example of Dewey's associations. And their relative privacy_or lack thereof-is instructive, as we consider how to rebuff our powerful spies.

Again, civil libertarians insist that the protection and expansion of liberty is unthinkable without privacy. But that is precisely what the labor movement did-as well as the civil rights movement in America, and the gay rights movement. Labor activists rarely if ever enjoyed privacy in which to work out their plans, and weigh courses of action. They were constantly hounded-or worse. In the 1930s, General Motors ruled the city of Flint, Michigan, the base of its car manufacturing, with an iron fist, crushing union activity. One worker complained that GM "so completely run this town and have it so well propagandized to their own good that one doesn't even talk here. You have no liberties at all. You couldn't even belong to a union and breathe it to a soul. That soul would probably be a spy." ${ }^{9}$

This did not stop GM workers from organizing one of the most remarkable strikes in US history, when they decided to sit down on the job, and subsequently occupied the factory floor for over a month. Together, the workers encouraged one another to endure ominous threats from the company. And they prevailed over GM, realizing many of their demands.

We must align ourselves again with intentional communities. Frankly, however, I am not sure of the path forward. For, the coordination of powers that I have described 
above, it faces considerable challenges. Once upon a time, Americans took part in a number of impromptu social groups, any number of evenings during the week-clubs, volunteer groups, bowling teams - and church or synagogue on weekends. This kind of habitual socializing is largely dead, as we are all caught up in the rat race, and society is secularizing. We have no time for easy socializing during the week; we are lucky enough to fall on the couch for an hour of TV each night. Furthermore, our suburban landscape, where most Americans now live, prioritizes the individual, and discourages casual encounters. Corner bars are a rarity; parks are, too. You have to drive in order to meet people in public spaces. This takes effort, which is sometimes hard to muster.

Since its inception, digital evangelizers have raved about the social prospects of the internet, which can bring people together from all over the world. People from very different backgrounds and persuasions can meet online, and interact. Except they don't. We are learning that digital technology has remarkable power to undermine democracy. On social media, people migrate to communities where they recognize their own. In these 'echo chambers,' they become more radicalized in their views, and less likely to sympathize, much less tolerate opponents. And media scholar Zeynep Tufekci points out the shortcomings of 'networked movements,' such as Occupy Wall Street in the US, and the Arab Spring. Despite initial success and attention, these movements largely folded. They grew quickly thanks to the help of digital media, but had shallow roots, Tufekci explains. ${ }^{10}$ They were not steeled, like the labor movement, through years of toil and trouble; they did not have the benefit of practicing coordination through adversity. Thus, networked movements quickly succumbed in the face of said adversity. There are other problems that doomed them, including the staunchly egalitarian nature of digital communication, which made activists less inclined to follow leaders, or point-persons who could negotiate with the government, and represent a political movement. In the US, we wait to see the fate of the Black Lives Matter movement, which, though also networked, has spawned activist communities that endure grueling marches and stand-offs with police and opponents, communities that understand how to demand legislative action.

That is a promising sign. Also promising is the curious change wrought by Covid - a change whose memory, I hope, might linger, and inspire. The pandemic gave many of us a taste of a different life. I will never forget the sound of my once busy street, midpandemic, eerily silent. Birds were chirping, when they would normally be drowned out by the highway; a clear blue sky beckoned. And people walked in the street. Neighbors waved at each other, chatted, and offered moral support, or help. The pandemic forced us to slow down, and reach out. It gave us pause to look around for once, and reassess what is valuable. It was a powerful lesson. If such attention would remain, if the memory of community power and support endures, our digital spies will have a hard time picking us off, and subduing us in turn. 